Abstracta Iranica Iranica

Revue bibliographique pour le domaine irano-aryen

Volume 32-33 | 2013

Comptes rendus des publications de 2009-2010

\title{
Yannis Toussulis. Sufism and the Way of Blame: Hidden Sources of a Sacred Psychology
}

Ève Feuillebois-Piérunek

\section{Q OpenEdition}

1 Journals

Édition électronique

URL : http://journals.openedition.org/abstractairanica/40334

DOI : 10.4000/abstractairanica.40334

ISSN : 1961-960X

\section{Éditeur :}

CNRS (UMR 7528 Mondes iraniens et indiens), Éditions de l'IFRI

\section{Édition imprimée}

Date de publication : 1 décembre 2013

ISSN : 0240-8910

\section{Référence électronique}

Ėve Feuillebois-Piérunek, "Yannis Toussulis. Sufism and the Way of Blame: Hidden Sources of a Sacred Psychology ", Abstracta Iranica [En ligne], Volume 32-33 | 2013, document 384, mis en ligne le 01 juillet 2016, consulté le 26 septembre 2020. URL : http://journals.openedition.org/abstractairanica/40334 ; DOI : https://doi.org/10.4000/abstractairanica.40334

Ce document a été généré automatiquement le 26 septembre 2020.

Tous droits réservés 


\title{
Yannis Toussulis. Sufism and the Way of Blame: Hidden Sources of a Sacred Psychology
}

\author{
Ève Feuillebois-Piérunek
}

\section{RÉFÉRENCE}

Yannis Toussulis. Sufism and the Way of Blame: Hidden Sources of a Sacred Psychology.

Weaton IL/Chennai, India, Quest Books, 2010, 282 p.

1 L'A., psychologue et co-directeur d'une organisation pour l'étude et la pratique du soufisme malāmatì (!), nous propose un livre dont la problématique et les contours sont mal définis. Le premier chapitre est une critique des présentations de type « New Age " du soufisme et insiste sur l'ancrage dans l'islam. Le second chapitre rappelle qu'il s'agit d'un phénomène diversifié et non univoque qui pousse sur un terreau syncrétique. Les chapitres 3 et 4 méditent sur les thèses universalistes de Gurdjieff, Idries Shah et J.C. Bennet. L'A., quant à lui, prend le parti de s'appuyer pour son étude sur la Malāmatiyya sur l'ouvrage de A. Golpanarli, Melamilik ve Malamiler, 1930 (!).

Après cette très longue dissertation sur l'approche à adopter, ponctuée d'enfoncement de portes ouvertes, l'A. consent enfin à entrer dans le vif du sujet. Le cinquième chapitre décrit la naissance de la Malāmatiyya au Nord-Est de la Perse et son extension vers l'Asie Centrale et l'Anatolie. Le sixième chapitre traite du début de la période ottomane. Le chapitre 7 s'intéresse à Pīr Nūr al-'Arabī, un naqšbandì à la fois proche de la malāmatiyya et d'Ibn 'Arabī. Le huitième chapitre étudie la malāmatiyya comme un phénomène contemporain de la Turquie kémaliste à travers l'interview d'un maître appelé Öziç. Les deux derniers chapitres sont plus théoriques et traitent du développement spirituel et de la surexistence de façon moderne et quelque peu New Age ! Notes, glossaire, bibliographie et index complètent le tout. 
3 Au final, le livre est décevant, car non scientifique et très dépendant de ses sources où les choses sont traitées de façon bien plus approfondie et académique. La description de la période contemporaine peut cependant présenter un certain intérêt, à cause du recours à des interviews de pratiquants.

\section{AUTEURS}

\section{ÈVE FEUILLEBOIS-PIÉRUNEK}

Université Sorbonne Nouvelle-Paris 3, Mondes iranien et indien, Paris 